\title{
Examining teachers' well-being during the pandemic: a mixed methods study on teachers' psychological, emotional and identity responses to online education
}

\author{
ISSN 2657-9774; https://doi.org/10.36534/erlj.2021.02.05 \\ Adrienn Fekete \\ University of Pécs \\ fekete.adrienn@pte.hu
}

\begin{abstract}
This mixed methods study investigates teachers' well-being in online education by looking at their linguistic and professional identity construction in the context of offline and online education. Teachers' identity construction in online education sheds light on their virtual identities (Kramsch 2009) as well as their emotional and psychological responses (Fekete 2020a, 2020b) to online education. The paper seeks to prove that identity construction is shaped by the language spoken by the person, the context of the person, and other individual differences of the person. Therefore, the author proposes that identity construction should be envisaged as a complex dynamic system of the person's individual differences that responds to changes in the levels of the system as well as environmental stimuli. Twenty-six teachers from eight countries participated in the research by completing a sentence completion task administered online. The large textual datasets were analyzed using qualitative content analysis that pointed out emerging themes. Then, descriptive statistics was employed to detect trends and frequencies, shining light on changes in the participants' emotions and identity construction in the various contexts. The findings point out that offline and online education shape teachers' identity construction as well as their psychological and emotional responses very differently. The results also pinpoint the difficulties teachers were faced with in online education and how these difficulties shaped their psychological, emotional and identity responses to the novel circumstances of their profession.
\end{abstract}

Key words: linguistic identity, professional identity, virtual identity, online education, teachers, emotions, complex dynamic systems, individual differences

\section{Introduction}

With the introduction of online instruction at all levels of education, teaching and learning processes drastically changed during the pandemic. Students and teachers alike were faced with the challenges of a novel learning environment, in which communication, interactions, instruction, evaluation and the provision of assistance took alternative forms by means of online platforms and electronic devices equipped with microphones and cameras. Traditional in-class learning and teaching became virtual and computerized, face-to-face interactions were replaced by virtual interactions, and people became virtual entities in the form of little squares or black dots on the computer screen. The technological and organizational changes resulting in online instruction led to uncharted psychological changes and emotional responses in the individuals participating in virtual education. The complexities of teachers' and learners' identities were further complicated by the cyber space, resulting in a new sense of self, the Virtual Self (Kramsch 2009) shining light on a person's virtual identity (Fekete 2019, Kramsch 2009).

The study employing a holistic look at identity seeks to fill three gaps in education research and applied linguistics research. First, the paper stresses the significance of understanding the subtleties of linguistic identity in education, which has been a marginally researched area. Second, the paper makes a contribution to the smaller expanse of research on teachers compared to the vastness of research 
involving learners. Since there is no education without teachers, their needs, desires, difficulties, and their complex features as individuals and as educators must be taken into consideration. Third, the investigation of virtual identities is a fully uncharted territory; thus, this mixed methods inquiry provides insights into teachers' linguistic as well as professional offline and online identities in an international context. The participating teachers' identities are mapped in terms of how they perceive themselves as English speakers and as English-speaking professionals (e.g. language teachers, professors, and researchers) and how they speak, write, think, and behave in online and offline classes. The rationale for employing mixed methods lies in the effort to offset the weaknesses of quantitative and qualitative research and to provide more comprehensive results. Descriptive statistics pinpoint trends and changes in teachers' identities when the participants switch to online instruction from face-to-face education, whereas the qualitative data shed light on the subtleties of these changes by explaining why and how these phenomena are happening.

\section{Theoretical overview}

\section{Identity in second language acquisition}

A person's identity may be understood in two ways: as a sense of Self that is distinct and different from others and as a sense of Self that makes the person similar to others (Rummens 2003). The former marks the person's individual identity, while the latter shines light on the person's social identity. Identity can be understood on various levels such as national, collective, social, communal, professional, and individual identity, while different types of identity such as cultural, gender, ethnic, and linguistic identity may be distinguished (Rummens 2003). Since the focus of this investigation is teachers' identity construction, the paper scrutinizes teachers' linguistic and professional identities in two contexts: offline and online education. The online manifestation of a person identity is called virtual identity (Kramsch 2009) which is also scrutinized in the paper.

The individual's identity has become understood as an entity that is not coherent, unchanging, constant, and homogeneous but rather diverse, heterogeneous, constantly changing and often contradictory (Block 2007, Butler 1997, Fekete 2020a, Pavlenko 2003). Kramsch (2009) labels the person's constantly changing identity construction as "subjectivity-in-process" that responds to environmental stimuli and the moment-by-moment interactions with other people. Being inherently linked to the individual, identity is connected to identification that links the individual to other people or groups. Identification indexing relationships of difference and similarity is important because people live in groups such as family, school, or professional organizations; therefore, identification is linked to collectivity and history. For this reason, identity is not independent of context and situation; rather, it emerges and is constructed and shaped in and via social interactions; therefore, identity may be perceived as social behavior characteristics of an individual or a group (De Fina \& Georgakopoulou 2012: 156-159).

Kramsch (2009: 6-15) explains second language acquisition (SLA) in terms of symbolic language use and desire. SLA is symbolic, because language is made up of a set of symbols conceived by a speech community to describe the world. Thus, by conforming to the linguistic and cultural norms of a speech community speaking the language as their native language $(\mathrm{NL})$, the language learner can gain access to or become a member in this community. However, the foreignness of the new language enables language learners to create their own subjective meanings, associations, emotions, feelings, fears, or anxieties associated with the new language (L2) that are unconventional for native speakers (NS). These unconventional meaning-making processes denote the second type of symbolic language use by learners. Furthermore, Kramsch adopted Kristeva's (1980) concept of desire in SLA to point out learners' desire for self-fulfillment in and via SLA. This desire reflects their inwardly generated identity drawing on their symbolic language use. On the one hand, desire pinpoints how SLA equips learners with a new 
mode of self-expression that can be a liberating experience, because learners can rid themselves of the linguistic and cultural constraints of their NL. On the other hand, learners may refuse the transformative potential of SLA and rather opt for their NL linguistic and cultural meaning-making processes, because the new language poses a threat to their existing identity associated with their NL and culture. Desire and symbolic language use pinpoint the transformative potential of SLA that learners may or may not embrace in the process of $L 2$ learning.

Based on the findings of her previous research (Fekete 2016, 2019, 2020a, 2020b), Fekete proposes that teachers' and learners' identity construction is inseparable from (1) the language they are learning or teaching, (2) from the learners and teachers themselves, and from (3) their other individual differences (IDs) (i.e., psychological characteristics such as motivation, anxiety, perfectionism etc.). Fekete (2019) takes a holistic stance in her research into linguistic and cultural identity and proposes that identity is inseparable from the person and their other characteristics. Identity shapes and is shaped by the person's emotions and other psychological characteristics and it responds to environmental stimuli. These processes are best envisaged as a complex dynamic system of IDs in which the person's identity construction is seen as the system-level behavior of a system made up of the person's IDs representing the levels of this complex and dynamic system.

\section{Virtual identity in computer mediated communication}

In principle, identity and the Self are the same but in cultural theory identity refers to the consciousness of the Self found in the individual (Longhurst et al. 2008: 141). In cultural studies the term Self is capitalized as it refers to and focuses on the individual. In the field of psychology, Neisser identifies five types of self-knowledge that he dubs the Ecological Self, the Interpersonal Self, the Extended Self, the Private Self, and the Conceptual Self. Kramsch (2009) adopts these types of selfknowledge in the field of applied linguistics to make sense of language learners' identity responses to SLA. In the process of learning a new language, Kramsch replaces the Private Self with the Reflective Self that reflects on the process of SLA. Furthermore, she adds two other types of self-knowledge: the Narrational Self and the Virtual Self. Therefore, virtual identity is understood as a type of identity that is activated when the person, who is referred to as the Virtual Self, goes online and engages in online communication. The virtual identity of the individual engaged in virtual communication is constructed and co-constructed in and via interactions with other online communicators.

In computer mediated communication (CMC) writing becomes a social-virtual activity in which the number of intended readers along with the speed of transmission increase, the text along with the Self become open to evaluation by others, and the Self is co-constructed in dialogue with others, thus creating the Virtual Self (Kramsch 2009: 155-185). In virtual communication historical time is suspended and time becomes reversible with the click of the mouse. Furthermore, the genre boundaries as well as the boundaries of space and time become blurred, and reality becomes hyper reality. In CMC, space is bent or high jacked in a way one can reach anyone in any corner of the world, and by hacking the computer one can pretend to be at a place where one is not. Time is also bent or high jacked, as it is relative and ahistorical, because $\mathrm{CMC}$ is disconnected from time and place. Furthermore, one can erase utterances from the past like they never happened by clicking the undo button and one can repeat history and bring past to the future by repeating old texts in the present or making additions to them in the present. Kramsch (2009: 173) calls this phenomenon time reversibility.

The Virtual Self enhances the ability of the individual to see without being seen and become a trickster of language (Fekete 2020b) who uses language in a way that others cannot. Identity construction online renders individuals agency and control as well as freedom to present themselves the way they wish to with the possibility to constantly reinterpret and change their self-representation. Yearning for control, agency, and freedom may lead to addiction to community sites, a so called cyber 
dependency (Kramsch 2009: 183) if one exclusively resorts to online communication to get feedback on the Self and to co-construct the Self at will.

$\mathrm{CMC}$ is often described as liberation for the shy and the under-confident, and it can be a great tool for tricksters, as well. CMS blurs the distinction between what is real and what is not or what is real communication and what is display communication. Kramsch (2009: 175) explains that "in the absence of embodied contact, virtual signifiers take on a life of their own, they become a reality in their own right - a hyper reality". For reality is high jacked by CMC and replaced by hyper reality the rules of genres or those of communication along with the real intentions of interactants are blurred or they simply disappear. In such a chaotic world, the agency and control gained by CMC are lost, making online communicators feel weak and vulnerable to other people online. Misunderstandings are more likely to happen as there are no rules for communication. Kramsch (2009) stresses that precisely because of this freedom computer users need to find and define the boundaries for communication if they are to have real understanding in a real interaction.

With the introduction of online education, teachers' and learners' virtual identity is activated when they synchronously or asynchronously interact with each other in speaking or in writing using online platforms and electronic devices that are equipped with cameras and microphones. Teachers' and students' linguistic identities have been examined before in the context of offline education (Fekete 2016, 2020a, 2020b, Kramsch 2009, Williams 2020), but mapping their virtual identity is an utterly unexplored area in education research.

\section{Empirical research on identity in education}

Related to the study of identity and SLA, holistic research approaches have gained momentum in the past two decades including post-structuralism, language ecology, and complex dynamic systems theory (CDST). These three holistic approaches have come to the fore, because they examine learners and their learning processes along with the learning environment in their complexity and entirety. The poststructuralist understanding of identity being changing, temporal, heterogeneous, socially constructed, and inseparable from the user of the language takes a holistic look at language learners and their identity construction (Fekete 2019, 2020b, Kramsch 2009, De Fina \& Georgakopoulou 2012). Kramsch (2009) and Fekete $(2019,2020 b)$ studied how transformative L2 learning is in learners' lives and how meaningfully it is lived by them, which, in turn, triggers powerful emotional and identity responses in them. Kramsch (2009) analyzed language learning metaphors associated with speaking and learning different languages in addition to analyzing language learners' linguistic autobiographies to cast light on major themes and processes shaping learners' linguistic, cultural, and ethnic identity construction in the U.S. Fekete (2020b) scrutinized Hungarian English majors' emotional responses to SLA, which, in turn, shone light on the participants' linguistic identity responses that were captured with the help of metaphors (desire, freedom, and pain) associated with SLA.

Language ecology considering the language, the learner, and the environment altogether with a regard for temporal changes and different timescales is another holistic approach in identity and SLA research. Fekete (2020a) studying multilingual English learners' linguistic and cultural identities drawing on the ecological perspective in a multiple case-study found that learners' different past language socialization and enculturation processes resulted in different linguistic and cultural identity patterns and responses, thus establishing a link between past, present, and future processes. A similar link was established in a case study by Williams (2020) who explored the narrative and identity construction of an ethnic Hungarian student born in Serbia but studying in Hungary at the time of the research. In a multiple case study, Cao (2011) explored the dynamic and situated nature of willingness to communicate (WTC) in English in the language classroom from an ecological perspective. Dragoescu Urlica and Stefanovic (2018) approached teaching English for specific purposes from the language 
ecological perspective. Daszkiewicz (2017) scrutinized the inherent and inseparable link between the language learner, the language, and the context of education by highlighting the educational role of language.

The third holistic approach that has become popular in SLA and education research involves complex dynamic systems theory (Larsen-Freeman 1997, 2017). Kramsch (2012) who draws on post-structuralism stresses the applicability and validity of CDST in the study of identity. In their book on the psychology of the language learner, Dörnyei and Ryan (2015) put forth a complex and dynamic approach to studying these learner characteristics and place the language learner's narrative identity in the focus of study. In the same vein, researchers have begun to adopt CDST in their empirical research into various IDs (e. g. motivation: Jiang and Dewaele 2015, language anxiety: Kasbi \& Shirvan 2017, WTC in English: Maclntyre \& Legatto 2011, self-concept: Mercer 2011, 2014). Fekete (2019) connected traditional IDs research and identity research drawing on CDST. She proposes the view of the language learner's identity construction as the system level behavior of a complex dynamic system in which individual learner characteristics constitute the levels of the system that horizontally and vertically shape the system's behavior, that is, the identity construction of learners through and in the $L 2$ they learn. This system is also shaped by environmental stimuli in the form of interactions with other $L 2$ speakers as well as the socio-cultural context. Figure 1 shows the interconnectedness of the language learner's various IDs and their identity construction.

Figure 1: Identity construction as a complex dynamic system of individual differences adopted from Fekete (2019: 230)

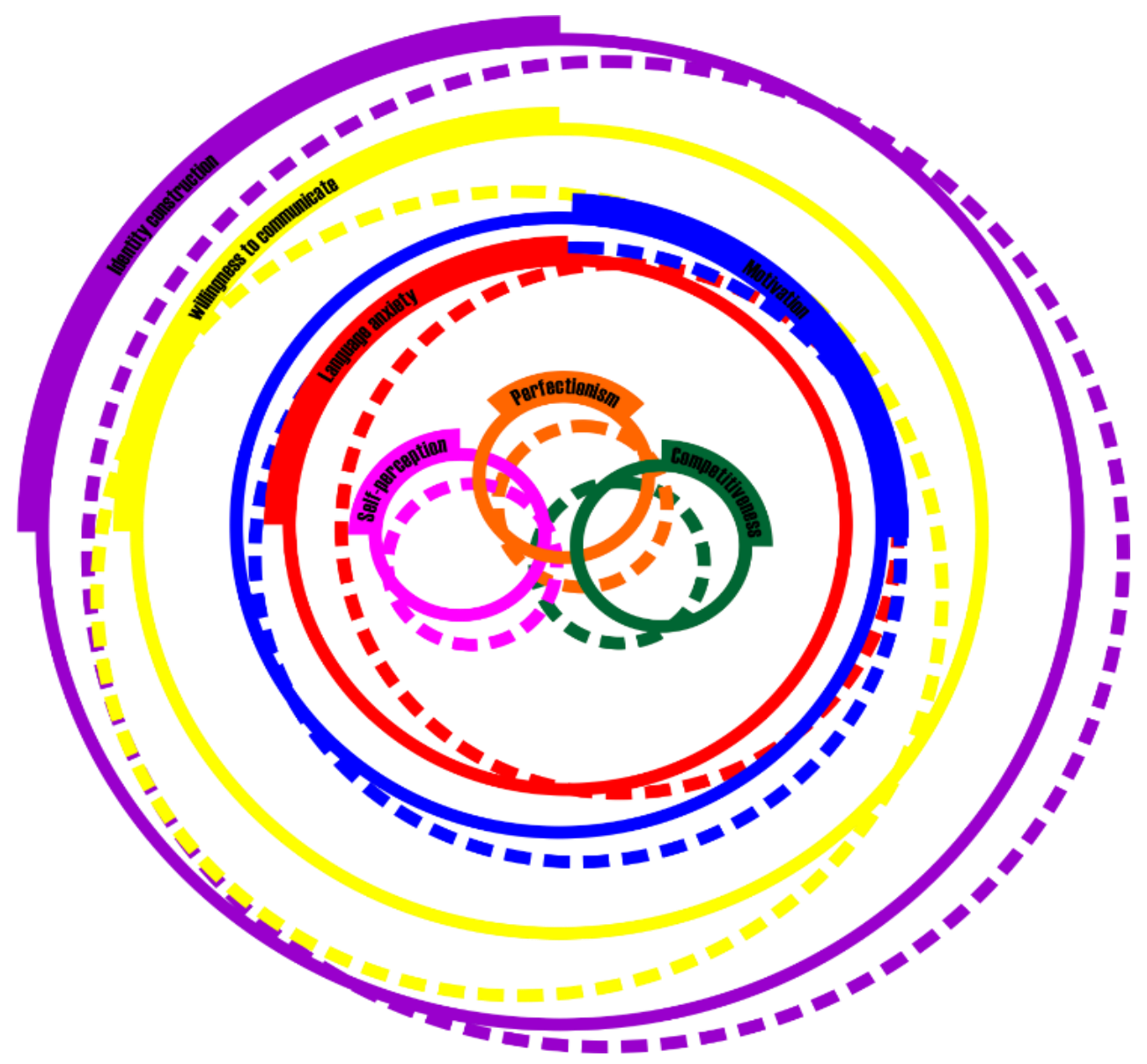


The intermittent lines stand for potential trajectories of the levels and the system, and these potential trajectories of IDs are idiosyncratic and subject to change over time. Despite the versatility of such a complex system, patterns of system behavior may be detected, making the system stable and changeable at the same time. The findings pinpointed that self-perception with respect to perceived language proficiency level and perceived aptitude, along with perfectionism, and competitiveness form a cyclic relationship, feeding into one another at one level within the learner. Changes at this level then feed into the learner's language anxiety at the next level up which affects their motivation to learn the language at the next level, which, then, shapes the learner's WTC in English. These IDs are envisaged as vertically and horizontally interacting levels of a system, which construct and shape the learner's identity as system-level behavior. Therefore, research into identity construction cannot be separated from research into IDs, as the two are inherently linked. Consequently, the present study is expected to shine some light on the participating teachers' IDs, as well.

\section{Methodology}

\section{Aim and context of study}

The aim of the study is to map English speaking teachers' linguistic, and professional offline and online/virtual identity construction to shed light on their psychological, emotional, and identity responses to offline and online education. The research was conducted in an international context with participants coming from eight countries. However, the distribution of teachers from these countries is unequal; therefore, conclusions from the different cultural backgrounds of the participants cannot be drawn.

\section{Research questions}

Table 1 presents the research questions answered in the inquiry.

Table 1: Research questions on teachers' linguistic, and professional offline and virtual identity

\begin{tabular}{|c|c|c|}
\hline Linguistic identity & Professional offline identity & $\begin{array}{l}\text { Professional online/virtual } \\
\text { identity }\end{array}$ \\
\hline $\begin{array}{c}\text { How do the } \\
\text { participants perceive } \\
\text { themselves as English } \\
\text { speakers? } \\
\text { How do they speak, } \\
\text { write, and think as English } \\
\text { speakers? }\end{array}$ & $\begin{array}{l}\text {-How do they perceive } \\
\text { themselves as teachers in } \\
\text { the classroom? } \\
\text { •How do they think students } \\
\text { see them in the classroom? } \\
\text { - How do they speak, write, } \\
\text { think, and behave in the } \\
\text { classroom? }\end{array}$ & $\begin{array}{c}\text { - How do they perceive } \\
\text { themselves as teachers in } \\
\text { online classes? } \\
\text { How do they think } \\
\text { students see them in } \\
\text { online classes? } \\
\text { - How do they speak, write, } \\
\text { think, and behave in online } \\
\text { classes? }\end{array}$ \\
\hline
\end{tabular}

\section{Participants}

Twenty-six teachers from eight countries participated in the research. The criteria for participation in the research involved 1) experience in teaching lessons/classes in English and 2) teaching experience in both offline and online education. Convenience and snowball sampling methods (Dörnyei 2007) were applied to find participants for the research. I contacted professors and teachers from different countries and invited them to participate in the research. I also asked them to forward the invitation letter to their colleagues at their workplace to recruit more respondents. Despite the sentence 
completion task being anonymous and easily accessible via Google Form, the response rate, being about 8-10 percent, was low. This may have been caused by three factors. First, the task required respondents to write sentences instead of answering simpler question types such as multiple-choice or Likert-scale items usually applied in questionnaires. This made the task longer and more time consuming. Second, teachers' various professional engagements may have prevented them from finding time to complete the task. Third, no reward was offered to respondents for their contribution, so participation was entirely voluntary.

Regarding the participants' professional background, twenty-three of them are university professors who teach courses in English and three of them are secondary school teachers of English. Table 2 shows the distribution of the participants coming from different countries.

Table 2: The distribution of the participants coming from different countries

\begin{tabular}{lllllllll}
\hline Hungary & Croatia & Poland & Slovenia & Slovakia & U.S. & Japan & Ethiopia & Total \\
\hline 15 & 5 & 1 & 1 & 1 & 1 & 1 & 1 & 26 \\
\hline
\end{tabular}

Twelve of the fifteen Hungarian respondents are university professors from four Hungarian universities, the three Hungarian teachers of English work at three different secondary schools in Pécs (Hungary), and the Croatian participants come from two Croatian universities. Twenty-one participants (81\%) are females and five (19\%) are males. Their age ranges from 23 to 64 years, with the average age being 47 years.

As for their positions at work, eight participants are assistant professors, six are associate professors, two are lecturers, one is a full professor, three are language teachers, and six work at a university but did not specify their position. The length of their employment in their current workplace ranges between 6 months and 30 years, with the average length of employment being 12 years. Regarding qualifications, nineteen respondents hold a PhD degree, six a master's degree, and one participant did not specify. Nineteen teachers are non-native speakers (NNS) of English, four of them are native speakers (NSs), and three consider themselves bilingual. The nineteen NNS teachers have learnt English for 30 years on average. The NNS participants perceive their English language proficiency level between $\mathrm{C} 1$ and $\mathrm{C} 2$ level, some of them mentioning the near-native proficiency level. Their responses indicate they have achieved the highest English language proficiency level a NNS can hope to attain. Save one respondent, all of them have learnt at least one other language in addition to English, so 25 of them are multilingual speakers irrespective of where they were born and in what context they have learnt their languages.

Their positions at work, the length of their employment, the length of English learning, and their reported proficiency level suggest that they are proficient English speakers as well as experienced English-speaking professionals being teachers, professors, and researchers. Regarding their experience in online education, eleven teachers reported to have had no experience in online teaching prior to the pandemic, while thirteen of them claimed to have had a little experience in using online tools and platforms (e. g. webinars, online meetings, and online applications such as Kahoot, Google Form, Google Drive, Drop Box, Padlet, Moodle, online one-on-one teaching), and only one reported to have designed online courses before the pandemic.

\section{Data collection instrument}

The instrument designed to collect data for the research was a sentence completion task administered anonymously online using Google Forms. The task was divided into sections inquiring after the participants' 1) linguistic identity in general, 2) their professional identity in offline classes, 3) their 
professional and virtual identity in online classes, 4) their camera use habits in online classes, 5) their classroom management in online classes, and 6) the participants' preferences for offline and online classes. In addition to these data sets, demographic information about the participants was collected, providing the professional and sociocultural context of the research. For the purposes of this study, the participants' answers to sections 1, 2, and 3 were analyzed. The items analyzed in this study are presented in Table 3.

Table 3: Items Included in Sections 1, 2, and 3

\begin{tabular}{|c|c|c|}
\hline $\begin{array}{l}\text { Section 1: } \\
\text { The participants' } \\
\text { linguistic identity }\end{array}$ & $\begin{array}{c}\text { Section 2: } \\
\text { The participants' professional offline } \\
\text { identity }\end{array}$ & $\begin{array}{c}\text { Section 3: } \\
\text { The participants' professional } \\
\text { virtual identity }\end{array}$ \\
\hline $\begin{array}{l}\text { When I speak in English } \\
\quad \text { (in general), I... } \\
\text { When I write in English } \\
\quad \text { (in general), I ... } \\
\text { When I think in English } \\
\quad \text { (in general), I... }\end{array}$ & $\begin{array}{c}\text { In an English class at university, I... } \\
\text { In an English class at university, I am... } \\
\text { In an English class at university, I } \\
\text { speak (like).... } \\
\text { In an English class at university, I write } \\
\text { (like)... } \\
\text { In an English class at university, I think } \\
\text { (like)... } \\
\text { In an English class at university, I } \\
\text { behave (like)... } \\
\text { In an English class at university, I see } \\
\text { myself ... } \\
\text { In an English class at university, } \\
\text { students see me... }\end{array}$ & $\begin{array}{c}\text { In an online English class, I ... } \\
\text { In an online English class, I am... } \\
\text { In an online English class, I } \\
\text { speak (like)... } \\
\text { In an online English class, I write } \\
\text { (like) ... } \\
\text { In an online English class, I think } \\
\text { (like) ... } \\
\text { In an online English class, I } \\
\text { behave (like)... } \\
\text { In an online English class, I see } \\
\text { myself ... } \\
\text { In an online English class, } \\
\text { students see me ... }\end{array}$ \\
\hline
\end{tabular}

The reason why fewer items were included in section 1 is that the major foci of the study were to compare online and offline education and to shed light on the details of online teaching. Since the task included many items about online and offline education, Section 1 was cut shorter to prevent the respondents from finding the items too repetitive and the task too long and monotonous.

The rationale for opting for this research instrument was twofold. On the one hand, the sentencecompletion task granted the participants freedom to finish the sentences without any pressure or any implication of what the desired answer might be, resulting in free associations and ideas. Furthermore, there was no requirement regarding the length of answers, so the respondents could write as much as they liked. Therefore, some answers were rather brief, while there were lengthy and detailed responses painting the full picture of the participants' point of view. On the other hand, the instrument was fully structured, so the sentences and thus the answers were comparable in the three contexts.

\section{Procedures}

The research idea with a tentative research design was presented to a group of approximately 30 international academics in the ERL Online Session held in March 2021. Based on their feedback and the positive reception of the research idea, the research instrument items were designed. Once the items were finalized, the task was piloted by a professor at the University of Pécs who has experience in teaching classes in English as well as in offline and online education. Drawing on her feedback, some items were clarified, and online administration was chosen for the purpose of ensuring anonymity and 
easy access. Data were collected in April 2021. Then, the answers to the items collected via Google Forms were copied to a word document where they were analyzed using qualitative content analysis and descriptive statistics.

Following the steps described in Saldana's (2013) coding manual, themes were color coded. Then, three cycles of coding were carried out to find recurring themes and patterns and to establish the hierarchical and horizontal relationship between the codes and the themes. When this process was finalized, frequencies were counted to point out trends and changes in the three contexts. Finally, qualitative data were used to complement the numerical results and to shed light on the subtle details of the phenomena indicated by descriptive statistics.

\section{Research methods}

This is a mixed methods inquiry incorporating quantitative and qualitative research. Quantitative research is normally applied to shine light on how things are in the sample examined (Dörnyei 2007). This type of research usually allows for the generalization of the findings if the sample size is large enough; however, in this paper, due to the small sample size, generalizations cannot be made. Based on the limited numerical data available, descriptive statistics was carried out to pinpoint trends and frequencies in the datasets. By contrast, qualitative research typically involving a small number of participants is normally used to explain subtle, often idiosyncratic, details shedding light on why and how certain phenomena have arisen (Dörnyei 2007). Nonetheless, the number of participants in the research is relatively large (N26), which allows the researcher to make some cautious and tentative conclusions based on the large qualitative data sets supported by some numerical data. Therefore, the study being mixed methods seeks to offset the weaknesses of both quantitative research and qualitative research and to provide more in-depth results and thus a more profound understanding of teachers' linguistic, professional, and virtual identities.

\section{Results and discussion}

\section{Teachers' linguistic identities}

In this section, I discuss how the teachers in the research perceive themselves as English speakers in three areas: 1) speaking in English, 2) writing in English, and 3) thinking in English, shedding some light on their linguistic identities in general. Table 4 presents the recurring themes in the three areas, numbers in bold signal significant changes across the three areas.

Table 4: Recurring themes across three areas of linguistic identity

\begin{tabular}{llll}
\hline Themes & $\begin{array}{l}\text { Speaking in } \\
\text { English }\end{array}$ & $\begin{array}{l}\text { Writing in } \\
\text { English }\end{array}$ & $\begin{array}{l}\text { Thinking in } \\
\text { English }\end{array}$ \\
\hline Feeling at ease & $\mathbf{7}$ & $\mathbf{9}$ & $\mathbf{1 3}$ \\
Feeling uncomfortable & 2 & - & - \\
Avoiding this situation & - & - & 2 \\
Self-monitoring & 5 & $\mathbf{1 0}$ & 1 \\
Fear of interacting with NSs & 2 & 0 & 0 \\
Identity response: Desire for self- & 2 & $\mathbf{5}$ & $\mathbf{5}$ \\
$\quad$ fulfillment (type 1 desire) & & & - \\
Linguistic and professional identity merged & 3 & 1 & - \\
Experiencing loss & 0 & 1 & \\
\hline
\end{tabular}

The frequency of feeling at ease in speaking, writing, and thinking in English is high; however, the increasing trend across areas shows that the more private the context is, the more at ease the 
participants feel in English. The least private context is speaking since the speaker is exposed to the environment and is surrounded by people. The most private context is thinking, as it is only accessible to the person engaged in thinking. The participants reported to feel "confident", "comfortable", and "natural" using English in the three contexts. The NNSs' proficient use of English in these areas was compared to the ease with which they use their mother tongue, which is a result corroborated by the participants' perceived high (near-native) proficiency level in English. Feeling uncomfortable was only noted in speaking, because speaking is the only irreversible and spontaneous act of language use. The respondents' self-monitoring is most active in speaking and in writing. In speaking, the participants tend to "think carefully before speaking" and try to "find the appropriate words" and "avoid making any mistakes". In addition to monitoring, the fear of interacting with NSs was mentioned by two participants.

T1: I feel really relaxed unless I speak with a native speaker. In that case, my level of anxiety in terms of finding obscure and scholarly words increases.

T2: I tend to change my pronunciation and style depending on the other speaker, especially if the other is a native speaker.

These statements are related to anxiety caused by the fear of making mistakes and the effort to maintain a positive linguistic identity (i. e. self-image) suggesting to the NS interactant that the teacher is native-like or at least highly proficient in English even when their English utterances are scrutinized by NSs (Medgyes 2017). NNS teachers of English are in a contradictory situation: they are both experts of the language (especially compared to students with limited proficiency levels) and learners of the language being NNSs. Their learner identity is more pronounced when they interact with NSs who can easily detect non-native-like phrases, structures, or pronunciation. These statements clearly demonstrate that the participants' identity construction corresponds to their "subjectivity-in-process" that is co-constructed in interactions with other people (Kramsch 2009).

Despite being a private activity in which the person is not exposed to other people or a public environment, writing in English entails the most monitoring by the participants. Notwithstanding the ample time they have to think over their thoughts, the reversibility of the act can make writing a long, and often, pain-staking process, especially for NNSs.

T1: I spend a lot of time finding the right formal language and vocabulary to use.

T2: It may also be a painstaking process in English, as I always double check my writing for mistakes and typos. I think much faster than I write, so I don't always write what I have in mind, resulting in typos or missing words, so it is annoying that I have to check my writing all the time. I don't want other people to think that these typos are more than lapses in concentration and focus, or clumsy typing skills.

These testimonies shine light on different aspects of the participants' identities. In speaking, one's pronunciation (if nothing else) can give away the person's non-native background; however, in writing using the appropriate words in the appropriate context (i. e. pragmatics) can make a positive impression as an English speaker/learner and as an English-speaking scholar on the reader, thus co-constructing the person's linguistic and professional identity favorably. These statements also point out two dimensions of perfectionism that the participants experience: high expectations of the Self by the individual and high expectations of the Self by other people (Flett, Hewitt, \& De Rosa 1996), even if the latter may only be a feeling of rather than a fact of pressure. Perfectionism has been found to be linked to selfperception, competitiveness, and anxiety (Gregerson \& Horwitz 2002, Tóth 2007), which is corroborated by the four excerpts above. The fourth testimony clearly points out the teacher's effort to sustain a positive English learner and professional identity driven by the fear of the reader associating potential typos and mistakes with the person's NNS background or inadequate language skills. Despite the, often, lengthy writing process, two participants associate the ease of writing in English with the academic discourse due to the professional requirement of having to write scholarly papers on a regular basis. 
The participants' identity responses to using English emerged in all three contexts; however, in the more private contexts of writing and thinking, it became more salient. Speaking in English was associated with self-fulfillment: "When I speak in English, I feel fulfilled." Writing in English was associated with pleasure: "I only write what I am pleased about", "I enjoy it", or "I find it more pleasurable to write for my own understanding". The most powerful identity response was associated with the desire (type 1) (Kramsch 2009) to become a different person in and via the L2 that is not limited by the linguistic, social, and cultural constraints of the NL. These participants embraced the transformative potential of L2 learning.

T1: When I speak in English, I feel free, happy, native-like and exhilarated like becoming a different person who is better and different than the native-tongue me.

T1: When I write in English, it is invigorating... and I love daydreaming in English. Perhaps because I prefer my English self over my mother-tongue self in those scenarios. English me is an improved, happy, confident, and successful person. It's much harder to live up to these standards in my mother tongue among my compatriots.

T2: When I write in English, I aim to be creative and unique.

T3: When I write in English, I have the feeling that I understand myself better.

The quotation by Teacher 2 indicates self-enhancement (Maclntyre, Noels \& Clément 1997), the need to be outstanding and unique in the ocean of English speakers. Teacher 3 points out how the essence of the Self is related to the use of English. Teacher 1 embraces the transformative potential of English learning to become the enhanced version of themselves in and via English. This is demonstrated by comparing the Self using English with the Self speaking the NL. These testimonies undoubtedly show how the use of the L2 permits the speaker to get rid of unfavorable linguistic, cultural, and social limitations and negative emotions imposed on the Self by the mother tongue as well as the culture and the people associated with it.

By contrast, the feeling of loss was noted by only one participant: "When I write in English, I tend to lose my sense of humor". Whether this loss is caused by humor being a very culture-specific discourse that may require vocabulary that NNSs rarely encounter or by linguacultural limitations or differences embedded in English compared to the mother tongue is hard to tell from such a concise statement.

Furthermore, the data point out that it is often impossible to separate the individual's linguistic identity from the person's professional identity when the job requires the use of English every day. Speaking in English was associated with the teaching component of being an academic, while writing in English was linked to the research requirement of the job. Interestingly, speaking was not associated with research (e. g. giving conference presentations), and the administration tier of the job was also ignored.

\section{Teachers' professional offline and virtual identities}

This section presents the findings related to teachers' professional offline and virtual identities exploring 1) what they do and how they feel in offline and online classes (Table 5), 2) how they speak, write, think, and behave as teachers (Tables 6, 7, 8, and 9), 3) how they see themselves (Table 10), and 4) how they think students see them in the two contexts (Table 11). Themes presented in Table 5 emerged in the data related to the following four items:

- $\quad$ In an English class at university/In an online English class, I...

- $\quad$ In an English class at university/In an online English class, I am... 
Table 5: Teachers' professional offline and online identities: what they do, how they feel, and what roles they assume in class

\begin{tabular}{lll}
\hline $\begin{array}{l}\text { In offline } \\
\text { classes }\end{array}$ & Themes & $\begin{array}{l}\text { In online } \\
\text { classes }\end{array}$ \\
\hline 7 & How they feel & \\
- & Feeling at ease & 5 \\
& Feeling uncomfortable & 7 \\
18 & What they do & - \\
5 & Teaching & 8 \\
- & Helping students & 12 \\
2 & Facing challenges & 2 \\
- & Doing their best & 4 \\
1 & using technology/gadgets & - \\
& Smiling at students & - \\
4 & The roles they assume & - \\
1 & Facilitator & - \\
1 & Expert & - \\
1 & Authority figure & - \\
1 & Participant & \\
\hline
\end{tabular}

Both the numerical and the textual data point out that in offline classes the teachers feel "extremely relaxed", "satisfied", "fine" and "more comfortable because of the face-to-face communication with the students". Feeling at ease comes from two sources: 1 ) being experienced teachers and 2) being able to interact with students in the classroom. They report no discomfort whatsoever in this context. In addition to their feeling of comfort, they exhibit self-awareness as teachers being aware of the various roles (e. g. facilitator, expert, authority figure, participant, entertainer) they assume in offline classes. Being untroubled in the classroom, they can focus on teaching (N18), interacting with students (e. g. talking with them or smiling at them) and helping them.

T1: I try to create the best possible learning experience for my students.

T2: I talk with my students a lot, I smile a lot, walk around, and become an active facilitator/teacher/participant/expert.

T3: I think I am serving a purpose which I also generally find satisfying - though I always feel I might have done more.

All three excerpts center around satisfying students' needs in the classroom. The second statement points out the various roles a teacher can assume; these roles correspond to the activities this teacher (T2) carries out in the classroom. The above roles and activities point to a student-centered teaching approach (Medgyes 2017). Student-centered teaching seems to be preferred by the respondents to teacher-centered teaching (e. g. frontal teaching with the teacher being the single authority figure in the classroom), because roles (such as facilitator, entertainer, participant: $\mathrm{N}$ : 6) suggesting the studentcentered approach outnumber the roles (expert, authority figure: N2) implying the teacher-centered approach. This result is corroborated by the focus placed by teachers on interacting with and helping students. In the third statement (T3), the teacher regards teaching as a personally and professionally satisfying activity indicating that one's linguistic identity may be inseparable from the person's professional identity when the profession entails speaking the language.

By contrast, online teaching shows a mixed picture. The number of teachers feeling uncomfortable in online education is higher than the number of teachers being at ease in online classes. Some reported to 
feel "relaxed", "confident", "comfortable", or "fine", whereas others noted negative feelings such as feeling "Ionely", "more reserved", "frustrated", too "occupied", or "nervous" about technology. In addition to experiencing discomfort, they seem to lose their self-awareness, because the focus in online education seems to shift entirely from the teachers to the students. Their professional identity seems to be in search of the new roles they are supposed to adopt in online education. Their primary focus on teaching seems to be lost at first sight. This may be explained by the great number of difficulties and novel challenges they are supposed to overcome. The difficulties the respondents reported are as follows:

- $\quad$ limited communication due to online tools,

- $\quad$ limited teaching methods and techniques,

- limited movements and the lack of body-language,

- technological problems and failures,

- $\quad$ preparing for classes is more-time consuming and labor intensive,

- $\quad$ learners' reticence to participate in online classes,

- $\quad$ lack of control over what students are doing at the end of the line, and

- $\quad$ being cut off from students (and often looking at a "blank screen").

Such problems can greatly hamper successful communication and teaching. Therefore, it is not surprising that teachers' verbal communication changed in online education (see Table 6).

Table 6: How teachers speak in offline and online classes

\begin{tabular}{lll}
\hline $\begin{array}{l}\text { In offline } \\
\text { classes }\end{array}$ & Themes & $\begin{array}{l}\text { In online } \\
\text { classes }\end{array}$ \\
\hline 6 & $\begin{array}{l}\text { How teachers speak } \\
5\end{array}$ & 7 \\
4 & Speech modification & 6 \\
0 & Speaking naturally & 4 \\
3 & Speaking a lot & 3 \\
- & Speaking little & 1 \\
& Speaking in English & 1 \\
2 & Speaking in the mother tongue (not English) & \\
1 & The roles teachers adopt & 1 \\
& Speaking like a teacher & 1 \\
0 & Speaking like an entertainer/actor & \\
0 & What they do & 5 \\
\hline
\end{tabular}

The data show that the number of teachers modifying and not modifying their speech in offline and online classes is almost identical. The speech modifications teachers make include, in both contexts, speaking more slowly and more clearly, in offline classes, speaking more formally and more briefly, and in online classes, speaking with pauses, speaking with more purposeful enunciation, and asking for confirmation by students. Research into classroom discourse (Walsh 2011) shows that teachers tend to speak more than students in the classroom, which is a finding confirmed by teacher data in this research. However, this trend changes in online education, indicating that some teachers tend to speak less in online classes. Speaking in English in classes is noted by the participants in both contexts; however, the use of the shared mother tongue may be justified due to the difficulties online education imposes on the participants. The roles teachers adopt do not emerge as a significant theme in the datasets; however, the role of actor/entertainer prevails in both contexts (e. g. giving a TED Talk in the 
classroom or being in a movie watched by students on their computers). Regarding the purpose of teacher talk, in offline classes the goal is to facilitate students' understanding and learning assuming that communication is unimpeded, while in offline classes the main objective is to make sure students can hear the teacher. Because in online classes the participants focus more on hearing and understanding of what is being said than on learning or teaching, teachers' primary focus is to resolve problems hindering communication. Successful communication is essential for successful and effective teaching and learning in education.

Regarding how teachers write in offline and online education, important changes can be observed in the two modes of instruction (see Table 7).

Table 7: Teachers' writing in offline and online classes

\begin{tabular}{lll}
\hline $\begin{array}{l}\text { In offline } \\
\text { classes }\end{array}$ & How teachers write & $\begin{array}{l}\text { In online } \\
\text { classes }\end{array}$ \\
\hline & The amount of writing & 3 \\
1 & Writing a lot & 7 \\
4 & Writing little & \\
& The place of writing & 1 \\
3 & Writing on the board & 10 \\
4 & Writing using a computer/device & 2 \\
- & Making hand-written notes & - \\
5 & Specifying the manner of writing & - \\
& The purpose of writing & - \\
2 & Writing for teaching purposes & 3 \\
\hline
\end{tabular}

Concerning the amount of writing done by teachers, about every fourth teacher reports to write little in online classes, while this ratio is only about one in eight teachers in offline classes. The reason for it was mentioned by two teachers. Due to the high demands of online teaching, teachers have to concentrate on multiple things in the classroom and writing would be an additional demand; therefore, they prepare the teaching materials (notes, ppt slides) in advance to avoid writing in their classes. They fear their slow writing/typing might further hinder communication. Four teachers noted that technological devices had been used in education before the pandemic, but online education made these devices the predominant means of instruction. In offline classes, teachers are aware of how they write: for example, "in an academic way", "with attention to detail", "in accordance with English logic", "clearly and unambiguously", or "impatiently". This aspect of their writing, however, becomes fully unimportant in online classes due to the complex nature of online communication. Moreover, the purpose of writing differs in the two modes of education. In offline classes, teachers' writing centers around teaching related issues such as "writing definitions", "setting a good example", or "providing feedback". By contrast, writing online becomes a social activity in which the participants write short messages and comments in chat windows. Teaching related writing by teachers in online classes takes the form of ppt slides and shared documents.

Examining how teachers think and what they think about provides insights into the respondents' cognition in offline and online education (see Table 8). 
Table 8: Teachers' cognition in offline and online education

\begin{tabular}{lll}
\hline $\begin{array}{l}\text { In offline } \\
\text { classes }\end{array}$ & Themes & $\begin{array}{l}\text { In online } \\
\text { classes }\end{array}$ \\
\hline 7 & What teachers think about & \\
3 & Thinking about students' needs & 3 \\
- & Thinking about classroom issues & - \\
- & Thinking about what students are doing & 2 \\
- & Thinking about how to make classes more enjoyable & 4 \\
- & Thinking about difficulties & 5 \\
1 & Thinking about their own environment & 2 \\
1 & Keeping up a role & - \\
- & Making changes in classes & - \\
& Working harder & 5 \\
- & How teachers think & 2 \\
2 & Thinking "normally" & 1 \\
7 & Thinking in English & 2 \\
\hline
\end{tabular}

Two dimensions of teachers' cognition surfaced in the data shining light on what teachers think about and how they think. Significant differences can be observed in the two domains in the two teaching contexts. The most salient aspects of teachers' cognition in offline classes are thinking about students' needs and how to motivate them as well as classroom related issues.

T1: I think like a student... and try to think from both students' and professors' perspectives.

T2: I think in very creative ways keeping in mind students' needs and problems. I improvise a lot in classes depending how students are behaving or feeling that day, what problems they may be having, so I am very open to making changes if I can better meet their needs that way.

T3: I think about my students.

The statements above suggest a general concern about students and teachers' efforts to satisfy their various needs. This effort is highlighted by the second teacher's readiness and willingness to improvise and change the lesson plan to adapt to the changing dynamics of the classroom. However, satisfying students' needs may take the form of role-playing by the teacher.

I have a meta-script running in my thoughts while teaching. I might be explaining/saying one think, while I might be thinking or feeling another. For example, I might feel a bit bored or frustrated with a certain topic or student, but I work to keep my outward appearance very focused on the topic at hand.

Being emotionally stable and impartial with students despite what the teacher may be thinking, or feeling is associated with maintaining a positive professional identity as well as living up to professional expectations set by the teacher and other people. Meeting such expectations reflects the teacher's perfectionism related to the teaching profession.

By contrast, in online classes, teachers are faced with new challenges, for example, overcoming difficulties resulting from the online environment, not seeing what students are doing, and making the lessons less monotonous. These problems become intensified when students do not (or cannot) turn on their camera enabling teachers to see students' reactions. Furthermore, teachers are more aware of their own environment - being their home and workplace at the same time. In summary, in offline classes teachers' thoughts center around positive teaching related issues, whereas in online classes thinking about solving problems comes before teaching. Regarding how they think in the two contexts, problems experienced in online classes do not allow teachers to reflect on how they think related to their teaching practice, as their primary concern is problem solving. Therefore, an important change is 
detected: while in offline classes, they can focus on the class, the students, and themselves, in online classes, they are pre-occupied with problems.

Similarly, teachers' behavior drastically changes in online education (Table 9).

Table 9: Teachers' behavior in offline and online education

\begin{tabular}{lll}
\hline $\begin{array}{l}\text { In offline } \\
\text { classes }\end{array}$ & Themes & $\begin{array}{l}\text { In online } \\
\text { classes }\end{array}$ \\
\hline 4 & How teachers behave & - \\
5 & Behaving in a culturally appropriate way & 4 \\
8 & Behaving in a student-centered way & 2 \\
- & Perceiving their own behavior positively & 9 \\
4 & Perceiving their own behavior negatively & 9 \\
2 & Behaving "normally" & - \\
& Behaving differently & - \\
1 & The roles teachers assume & - \\
1 & Behaving like a leader & - \\
1 & Behaving like an expert & - \\
\hline
\end{tabular}

A sharp contrast may be observed in teachers' behavior in the two contexts. In offline classes, teachers prioritize students' needs and seek to behave linguistically and culturally appropriate ways. Although in online classes they continue to keep up their student-centered behavior, behaving in a linguistically and culturally appropriate manner becomes secondary. Instead, they work to act in a way that may be perceived as "normal" by students at a time that is far from normal and is replete with problems. This finding is evidenced by the sharp contrast in teachers' self-perception in the two contexts. In offline classes, their self-perception is entirely positive, and they are aware of the roles they assume as teachers. However, in online classes, their self-perception is overwhelmingly negative, and they ignore the roles they assume. This contrast may be explained by the increased demands of online education.

Finally, how teachers see themselves and how they think students see them are compared in Tables 10 and 11.

Table 10: Teachers' self-perception in offline and online education

\begin{tabular}{lll}
\hline $\begin{array}{l}\text { In offline } \\
\text { classes }\end{array}$ & Themes & $\begin{array}{l}\text { In online } \\
\text { classes }\end{array}$ \\
\hline 7 & How teachers see themselves & \\
- & Positive self-perception & 4 \\
4 & Negative self-perception & 2 \\
1 & Identity co-constructed by students & 4 \\
1 & Identity co-constructed by other teachers & 2 \\
& Becoming a different a person & - \\
4 & The roles teachers assume & 10 \\
6 & Teacher & 8 \\
- & Facilitator & 4 \\
3 & Counselor & 1 \\
2 & Expert & - \\
1 & Entertainer & 1 \\
\hline
\end{tabular}




\begin{tabular}{lll}
\hline 1 & Partner & - \\
- & Person & 1 \\
1 & Proficient English speaker & - \\
\hline
\end{tabular}

Table 11: How teachers think students see them in offline and online education

\begin{tabular}{lll}
\hline $\begin{array}{l}\text { In offline } \\
\text { classes }\end{array}$ & Themes & $\begin{array}{l}\text { In online } \\
\text { classes }\end{array}$ \\
\hline 10 & How teachers assume students see them & \\
- & Positive self-perception & 5 \\
- & Negative self-perception & - \\
& As a disembodied entity on the screen & 4 \\
10 & The roles teachers adopt & \\
- & Teacher & 9 \\
3 & Counselor & 4 \\
2 & Facilitator & 1 \\
1 & Expert & - \\
1 & Authority figure & 2 \\
1 & Person & - \\
\hline
\end{tabular}

Teachers' self-perception in offline classes is entirely positive and mostly positive in online classes (Table 10). Interestingly, they assume students perceive them more favorably than how they see themselves in the two contexts (Table 11). However, this picture is more subtle than that in online classes. Teachers fear they become disembodied entities for students in online education instead of flash-and-blood people. Another notable change concerns how teachers see their teacher roles and how students perceive these roles. While teachers tend to see themselves as teachers, facilitators, and counselors in online classes, they assume students rather see them as teachers and counselors. Consequently, teachers assume a new role: they become counselors in online education. This finding suggests that teachers' most important function in online education, besides teaching, is to help students to overcome the myriad of difficulties online education imposes on them.

\section{Summary of findings}

Regarding teachers' linguistic identity construction, it is largely characterized by positive emotions, self-fulfillment, and the desire for a new mode of self-expression in and via English. They feel at ease when speaking, writing, and thinking in English. The more private the context is, the more comfortable they feel. On the other hand, conversing with NSs can pose a threat to the positive linguistic identity construction of the participants by pointing out their learner identity and their NNS background. Writing in English may also pose a threat to their positive linguistic identities; therefore, most NNS teachers painstakingly monitor their writing to find the appropriate phrases and to avoid erring in their writing. The findings of the study confirm that identity construction is linked to IDs. The participants' linguistic and professional identity construction shapes and is shaped by their other IDs such as their anxiety, selfperception, and perfectionism. These results are in line with the author's previous findings on the interrelatedness of IDs and identity construction in the context of SLA (Fekete 2019).

Sharp differences can be detected in the participants' professional identity construction in offline and online education. While their self-perception, self-confidence, and self-awareness underlying their professional identities in the classroom are entirely positive, their identity construction in online classes shows a rather mixed picture. Their self-perception is mostly negative, their self-confidence is low, and 
they tend to lose their self-awareness and the various roles they usually assume in offline classes. In the classroom, they can focus on themselves (e. g. how they think, speak, and write, who they are, and what roles they assume), the students, and teaching. However, in online classes, they can only concentrate on the myriad of problems they are expected to overcome. While in offline classes, they assume various roles (expert, teacher, facilitator, entertainer etc.), in online classes, teachers mostly become counselors whose most important duties involve solving problems and helping students. In offline classes, they focus on teaching and satisfying students' needs because they experience no problems whatsoever. By contrast, in online classes, their priorities drastically change. First, they need to solve (technical) problems and make communication successful - two things that are prerequisites of successful teaching and learning processes. The lack of problems and their high self-confidence level result in low levels of anxiety in offline classes; however, in online classes the myriad of problems, impeded communication, and low levels of self-confidence lead to high levels of anxiety experienced by teachers. This anxiety, however, does not stem from language use but from the novel challenges of online education.

\section{Conclusions}

There are salient differences in teachers' linguistic, and professional offline and online identities. Their professional offline identities are perceived as most positive and successful. Their self-perception is overwhelmingly positive, they report no problems in the classroom where they regard themselves as successful and motivating teachers. However, in the classroom they do not concentrate on themselves; rather, they prioritize students and other classroom related issues. Their linguistic identity in and via English is mostly positive and is characterized by a sense of success, achievement, and self-fulfillment. They largely focus on themselves, they perceive their English-speaking Self as mostly positive, and they embrace the transformative potential of English that shapes their linguistic identities. However, they may experience high levels of anxiety related to using English as NNSs. The least positive and the least successful teacher identity construction emerges in the context of online education. The teachers' professional virtual identity is characterized by struggle, anxiety, and the lack of self-confidence. Their self-perception ranges from mixed to negative and they experience a multitude of losses in online education.

The losses teachers experience are associated with their individual, professional, and virtual identities. As a person they lose their physical body in the cyberspace, and they lose their sense of Self by becoming disembodied entities on computer screens. As a teacher, unforeseen problems in the virtual environment force them to abandon their usual teacher roles, and they often lose control over what is happening in the online classroom owing to these problems. Furthermore, they lose their sense of the students' Selves and their physical bodies. Students also become disembodied entities on teachers' computer screens. Going online, teachers' Virtual Self has little or no knowledge of the rules of communication in online classes and they may be unaware of what is real communication and what is display communication in the online classroom. For example, they may wonder if students' verbal comments or notes in chat boxes are real communication or display communication. In display communication students may only be pretending to follow the class while, in the real world, they may be doing something else. Teachers may also wonder about what students really mean in verbal and written interactions. They may be deceived by student tricksters engaged in display communication. Communication breakdowns may occur when NNS teachers and students mean different things when saying or writing something drawing on their subjective and unconventional meaning-making processes that are further complicated by the lack of communication rules and boundaries in CMC. This situation makes teachers feel weak and vulnerable in online education. This finding is substantiated by the frustration, anxiety, and discomfort that the teachers in the study reported to experience in online education. 
In addition to teachers' identity construction in various contexts, the paper shines light on the kind of difficulties teachers face in online education and their emotional and identity responses to these novel challenges. Since there is no offline or online education without teachers, it is important to examine their needs and struggles, which became an even more salient issue in online education. The success of online education hinges - to an even greater extent - on the teacher's ability to solve the additional problems caused by CMC and to juggle the novel demands of online teaching. The findings of the study highlight teachers' search for their new roles in online education. It seems that the numerous problems related to online education along with students' expectations of teachers all point to the emergence of a new teacher role: the counselor teacher. This new role raises questions about the teaching profession and teachers' role in education, for instance, whether it is a realistic expectation of teachers to become counselors all of a sudden, or whether teachers are qualified (or experienced enough) to become counselors, or how this new role can or should be incorporated in teacher education, or who will counsel teachers when they need help. These questions need to be considered carefully by educators and decision makers when the processes and the consequences of online education are examined.

Finally, the study confirms that the individual's identity construction cannot be separated from the context of the person. The findings show that offline and online education shape teachers' identity construction very differently, resulting in different professional identities in the two contexts. This result pinpoints that identity is constructed and co-constructed in interactions with other people and is greatly affected by the environment. The results also point out that identity shapes and is shaped by other IDs; therefore, identity construction should be seen as a complex dynamic system of the person's IDs. In this complex system, the levels of the system horizontally and vertically interact with one another as well as the environment. The paper also corroborates that language cannot be separated from the person using the language, and in the case of teachers (teaching in the L2), their linguistic and professional identities are inherently linked, since their job involves interactions in the $L 2$.

\section{References}

Block, D. (2007). Second language identities. London: Continuum.

Butler, J. (1997). Excitable speech: The political promise of the performative. New York: Routledge.

Cao, Y. (2011). Investigating situational willingness to communicate within second language classrooms from an ecological perspective. System, 39(4), 468-479.

Daszkiewicz, M. (2017). Educational role of language - its multifaceted scope and its social complexity, in: M. Daszkiewicz, E. Filipiak, A. Wasilewska, R. Wenzel (Eds.). Educational Role of Language (pp. 4762). Gdansk Publishing House "Harmonia".

De Fina, A., Georgakopoulou, A. (2012). Analyzing narrative: Discourse and sociolinguistic perspectives. Cambridge: Cambridge University Press.

Dörnyei, Z. (2007). Research methods in applied linguistics: Quantitative, qualitative and mixed methodologies. Oxford: Oxford University Press.

Dörnyei. Z., Ryan, S. (2015). The psychology of the language learner revisited. New York: Routledge.

Dragoescu Urlica, A. A., Stefanovic, S. (2018). Ecolinguistic qualities of the optimal English language learning experience. International Journal for Quality Research, 12(2), 537-646.

Fekete, A. (2016). Multilingual speakers' reflections on multilingualism, multiculturalism and identity construction, in: M. Lehmann, R. Lugossy, \& J. Horváth (Eds.), UPRT 2015: Empirical studies in English applied linguistics (pp. 74-90). Pécs: Lingua Franca Csoport.

Fekete, A. (2019). Exploring advanced English learners' multilingual identity construction from multiple perspectives. (Doctoral dissertation, University of Pécs). http://nydi.btk.pte.hu/content/exploringadvanced-english-learners-multilingual-identity-construction-multiple-perspectives?language=en Accessed on 31 October 2020. 
Fekete, A. (2020a). A case study on advanced English learners' different second language socialization and enculturation experiences from the perspective of language ecology, in: A. Fekete, M. Lehmann, K. Simon (Eds.). UPRT 2019: Empirical Studies in English Applied Linguistics (pp. 143-161). Pécs: Lingua Franca Csoport.

Fekete, A. (2020b). Desire, freedom, and pain in English learners' emotional responses to SLA: A holistic look at English learners' multilingual identity construction. ERL Journal, 2(4), 84-99.

Flett, G. L., Hewitt, P. L., De Rosa, T. (1996). Dimensions of perfectionism, psychosocial adjustment, and social skills. Personality and Individual Differences, 20(2), 143-150.

Gregersen, T., Horwitz, E. K. (2002). Language learning and perfectionism: Anxious and non-anxious language learners' reactions to their own oral performance. Modern Language Journal, 6(4), 562-570.

Jiang, Y., Dewaele, J. M. (2015). What lies beneath the surface? A longitudinal perspective on fluctuations of ideal and ought-to L2 self among Chinese learners of English. IRAL, 53(3), 331-354.

Kasbi, S., Shirvan, M. E. (2017). Ecological understanding of foreign language speaking anxiety: emerging patterns and dynamic systems. Asian-Pacific Journal of Second and Foreign Language Education, 2(2).

Kramsch, C. (2009). The multilingual subject. Oxford: Oxford University Press.

Kramsch, C. (2012). Why is everyone so excited about complexity theory in applied linguistics? Mélanges CRAPEL, 33, 9-24.

Larsen-Freeman, D. (1997). Chaos/complexity science in second language acquisition. Applied Linguistics, 18(2), 141-165.

Larsen-Freeman, D. (2017). Complexity theory: The lessons continue, in: L. Ortega \& Z. H. Han (Eds.), Complexity theory and language development: In celebration of Diane Larsen-Freeman (pp. 51-58). Amsterdam \& Philadelphia: John Benjamins Publishing Company.

Longhurst, B., Smith, G., Bagnall, G., Crawford, G., Ogborn, M., Baldwin, E., McCracken, S. (2008). Introducing cultural studies. London \& New York: Pearson Longman.

Macintyre, P. D., Legatto, J. J. (2011). A dynamic system approach to willingness to communicate: Developing an idiodynamic method to capture rapidly changing affect. Applied Linguistics, 32(2), 149171.

Maclntyre, P. D., Noels, K. A., Clément, R. (1997). Biases in self-ratings of second language proficiency: The role of language anxiety. Language Learning, 4(2), 265-287.

Medgyes, P. (2017). The non-native teacher (2nd ed.). Callander: Swan Communication.

Mercer, S. (2011). Language learner self-concept: Complexity, continuity and change. System, 39(3), 335-346.

Mercer, S. (2014). The self from a complexity perspective, in: S. Mercer \& M. Williams (Eds.), Multiple perspectives on the self in SLA (pp. 160-176). Bristol: Multilingual Matters.

Pavlenko, A. (2003). "I never knew I was bilingual": Reimagining teacher identities in TESOL. Journal of Language, Identity, and Education, 2(4), 251-268.

Rummens, (2003). J. A. Conceptualising identity and diversity: Overlaps, intersections, and processes. Canadian Ethnic Studies, 35(3), 10-25.

Saldana, J. (2013). The coding manual for qualitative researchers. Los Angeles, London, New Delhi, Singapore, \& Washington DC: Sage.

Tóth, Z. (2007). Predictors of foreign language anxiety: Examining the relationship between anxiety and other individual learner variables, in: J. Horváth \& M. Nikolov (Eds.), UPRT 2007: Empirical studies in English applied linguistics (pp. 123-148). Pécs: Lingua Franca Csoport.

Walsh, J. (2011). Exploring classroom discourse: Language in action. Routledge.

Williams, T. A. (2020). On the border bus: Narrative and identity construction in an English major from Vajdaság/Vojvodina, in: A. Fekete, M. Lehmann, \& K. Simon (Eds.). UPRT 2019: Empirical Studies in English Applied Linguistics (pp. 331-347). Pécs: Lingua Franca Csoport. 